\title{
Research on influence factors of VSC's efficient operation
}

\author{
Jie Lu ${ }^{1, a}$, Xin Fa Tang ${ }^{2, b}$ \\ ${ }^{1}$ Research Center of Jiangxi Local Culture, Jiangxi Science \& Technology Normal University, Nanchang, 330013, China. \\ ${ }^{2}$ Tourism School, Jiangxi Science \& Technology Normal University, Nanchang, China \\ a154416372@qq.com, ${ }^{b} x i n f a t a n g @$ sina.com.cn
}

\begin{abstract}
VSC is a league made up of some software firms of different advantages and resources aiming at common software developing tasks or relative services. the result of cooperation is based on it's cooperative efficiency. This article tries to find out and compute those primary influence factors of VSC' operation through mutiple statistical method and RST, and then some suggestions are given.
\end{abstract}

\section{VSC's connotation}

VSC is abreviation for Virtual Software Corporation which is one kind of Virtual Enterprise. With the development of information technique, the hardware which software system relies on has changed much, at the same time, the scale, complexity and development cost of software system are increasing evidently. It's hard for one software firm to meet all these needs only depends its own resources and knowledge. As a creative organization form, VSC provides a fresh drain of thought to solve those problems mentioned above.

This paper considers that VSC is a league made up of several software firms of different advantages and resources aiming at a better job in common software development tasks or relative services.

\section{Analysis on influence factors of VSC's efficient operation}

Till now, little research has been done to find out pivotal influence factors in VSC's operation. This paper strives to reveal the factors by multiple statistics method and RST based on questionnaire survey.

\subsection{Truth analysis on influence factors of VSC's operation}

To make a thorouth study on influence factors of VSC operation, 3 different analytic methods are adopted, i.e., to gather data by questionnaire survey, factor analysis method is taken to find out those influence factors and RST is used to compute those factors' relative importance.

\subsection{Questionaire devising and data gathering} Questionnaire survey was taken to get data which are needed in truth analysis, further analysis was done by one of multiple analysis methods__ factor analysis method with SPSS12.0. in this survey, Sends out questionnaire 200, reclamation effective questionnaire 122 , recovery pecent $61 \%$, Invalid questionnaires (with incomplete answers) were eliminated, 103 valid questionnaires, the valid questionnaire return rate is $84.4 \%$.

\subsection{Reliability testing}

Reliability is regarded as criterion to test the consistency and stability of gathered data. In this research, Cronbach's Alpha was adopted. Table 1 was gotten by SPSS: 
Tab 1: the Result of Reliability Testing

\begin{tabular}{|c|c|c|}
\hline $\begin{array}{c}\text { Cronbach's } \\
\text { Alpha }\end{array}$ & $\begin{array}{c}\text { Cronbach's Alpha } \\
\text { Based on } \\
\text { Standardized Items }\end{array}$ & N of Items \\
\hline .798 & .804 & 29 \\
\hline
\end{tabular}

Cronbach's Alpha is 0.798, Cronbach's Alpha Based on Standardized Items reaches 0.804 , so we can believe that this questionnaire's reliability is satisfying and meets statistics analysis.

\subsection{Factor analysis}

From table 2, KMO is 0.760 which indicates these data are suitable for factor analysis, Bartlett's Test of Sphericity .000 , less than 0.01 , which shows that correlation matrix isn't identity matrix and suitable too.

Tab 2: the Result of KMO Measure of Sampling and Bartlett's Test of Sphericity

\begin{tabular}{|c|c|c|}
\hline \multicolumn{2}{|c|}{$\begin{array}{l}\text { Kaiser-Meyer-Olkin Measure of } \\
\text { Sampling Adequacy. }\end{array}$} & .760 \\
\hline Bartlett's Test of & Approx. & 3068.15 \\
\hline Sphericity & Chi-Square & 0 \\
\hline & df & 406 \\
\hline & Sig. & .000 \\
\hline
\end{tabular}

9 factors were extracted in principal component $78.504 \%$. After a rotation converged in 7 iterations, analysis as seen, totle variance explained reach table 3 could be gotte

Tab 3: Rotated Component Matrix

\begin{tabular}{|c|c|c|c|c|c|c|c|c|c|}
\hline & \multicolumn{9}{|c|}{ Component } \\
\hline & 1 & 2 & 3 & 4 & 5 & 6 & 7 & 8 & 9 \\
\hline $\mathrm{C} 1$ & -.003 & .903 & .162 & -.011 & -.030 & .052 & .004 & -.031 & -.055 \\
\hline $\mathrm{C} 2$ & -.105 & .070 & .325 & .172 & -.122 & .134 & -.144 & .297 & .134 \\
\hline $\mathrm{C} 3$ & -.013 & .075 & .708 & .033 & .009 & -.137 & -.067 & .146 & .126 \\
\hline $\mathrm{C} 4$ & .110 & .197 & .334 & .134 & -.087 & .630 & .248 & .231 & -.041 \\
\hline $\mathrm{C} 5$ & .156 & .229 & .118 & .063 & -.150 & .587 & -.303 & -.010 & -.152 \\
\hline C6 & .013 & .094 & .879 & .057 & .058 & .132 & -.038 & -.128 & -.202 \\
\hline C7 & .103 & -.117 & .008 & -.119 & .034 & -.016 & -.187 & .922 & .064 \\
\hline $\mathrm{C} 8$ & .043 & .059 & .160 & .133 & .167 & -.007 & -.191 & .219 & .054 \\
\hline C9 & .052 & .051 & .920 & .136 & .085 & .104 & .062 & -.005 & -.057 \\
\hline $\mathrm{C} 10$ & .024 & .058 & .919 & .074 & .079 & .174 & .067 & .025 & -.067 \\
\hline $\mathrm{C} 11$ & -.034 & .961 & .052 & .087 & .041 & .086 & .002 & -.001 & -.056 \\
\hline $\mathrm{C} 12$ & .160 & .049 & .081 & .037 & -.070 & -.093 & .778 & -.030 & .050 \\
\hline $\mathrm{C} 13$ & -.047 & .934 & .014 & .033 & .020 & .042 & -.005 & -.072 & .005 \\
\hline C14 & .980 & -.051 & -.022 & -.002 & .008 & -.010 & .025 & .034 & .027 \\
\hline $\mathrm{C} 15$ & -.038 & .094 & .181 & .305 & .224 & .441 & .728 & .144 & .055 \\
\hline $\mathrm{C} 16$ & .944 & -.052 & -.047 & .002 & .058 & .035 & .018 & .019 & .018 \\
\hline C17 & -.038 & -.010 & .030 & .881 & .059 & .076 & -.025 & .017 & .030 \\
\hline
\end{tabular}




\begin{tabular}{|l|r|r|r|r|r|r|r|r|r|}
$\mathrm{C} 18$ & .021 & .091 & .071 & $\mathbf{. 9 1 8}$ & .033 & .122 & -.010 & -.037 & -.032 \\
$\mathrm{C} 19$ & -.016 & -.023 & .072 & .453 & .045 & .103 & .373 & .487 & -.037 \\
$\mathrm{C} 20$ & -.017 & .117 & .195 & $\mathbf{. 8 8 3}$ & .052 & .041 & -.017 & -.025 & -.009 \\
$\mathrm{C} 21$ & $\mathbf{. 9 4 8}$ & .011 & .028 & -.044 & .062 & .065 & .048 & .016 & .019 \\
$\mathrm{C} 22$ & $\mathbf{. 9 4 3}$ & -.012 & .019 & .004 & .026 & .038 & .027 & .066 & .009 \\
$\mathrm{C} 23$ & $\mathbf{. 9 2 9}$ & -.024 & .065 & -.013 & -.011 & -.013 & .010 & -.046 & .006 \\
$\mathrm{C} 24$ & -.042 & -.004 & -.021 & .095 & .282 & $\mathbf{. 8 0 4}$ & -.068 & -.092 & .108 \\
$\mathrm{C} 25$ & -.020 & -.009 & .032 & .045 & $\mathbf{. 9 1 6}$ & -.001 & -.112 & -.013 & -.088 \\
$\mathrm{C} 26$ & .126 & .095 & .124 & .063 & $\mathbf{. 8 8 5}$ & .120 & -.056 & .002 & -.074 \\
$\mathrm{C} 27$ & .032 & -.005 & .011 & .042 & $\mathbf{. 9 3 2}$ & .032 & .000 & .031 & .040 \\
$\mathrm{C} 28$ & -.046 & $\mathbf{. 9 5 2}$ & .070 & .103 & .056 & .096 & .010 & .008 & -.042 \\
$\mathrm{C} 29$ & .073 & -.126 & -.096 & -.014 & -.096 & .017 & .025 & .052 & $\mathbf{. 8 1 7}$ \\
\hline
\end{tabular}

Extraction Method: Principal Component Analysis.

a Rotation converged in 7 iterations.

Rotation Method: Varimax with Kaiser

Normalization.

Combined with table 4 and questionnaire, 7 factors were found out:

Factor 1: composed by C14、C21、C16、C22, named definity of software module; Factor 2: composed by $\mathrm{C} 11, \mathrm{C} 28 、 \mathrm{C} 13 、 \mathrm{C} 1$, named profit allocation; Factor 3: composed by C9、C10、C3, named cooperation attitude; Factor 4: composed by C18、C20、C17, named employee quality; Factor 5: composed by C27、C25、C26, named developing conditions; Factor 6: composed by C24、C4、C5, named communication ways; Factor 7 : composed by C12、C15, named learning and creation; Factor 8: composed by $\mathrm{C} 7$, named developing standard; Factor 9: composed by C29, named management's support.

As is shown in the figure 1:

Figure 1: the primary influence factors of VSC' efficient operation

\section{Analysis on importance of influence factors on RST}

\subsection{Train of analytic thought}

(1) To compute relative importance of influence factors, formula is:

$$
I(P)=\sum_{i=1}^{n} \frac{\left|X_{i}\right|}{|U|}\left[1-\frac{\left|X_{i .}\right|}{|U|}\right]=1-\frac{1}{|U|^{2}} \sum_{i=1}^{n}\left|X_{i}\right|^{2}
$$

(2) Further analysis of each factor in terms of the 
result computed above.

\subsection{Computing and analysis on importance influence factors of VSC' efficient operation}

\section{(1) Computing influence factors'importance}

According to the train of analytic thought, RST was adopted to compute factors'importance. This information system of RST derived from the questionnaire, so there are 9 attributes in this information system and 103 records, a software program run in MATLAB6.5 was devised to do the job. The computing results are saved in an array IMP:

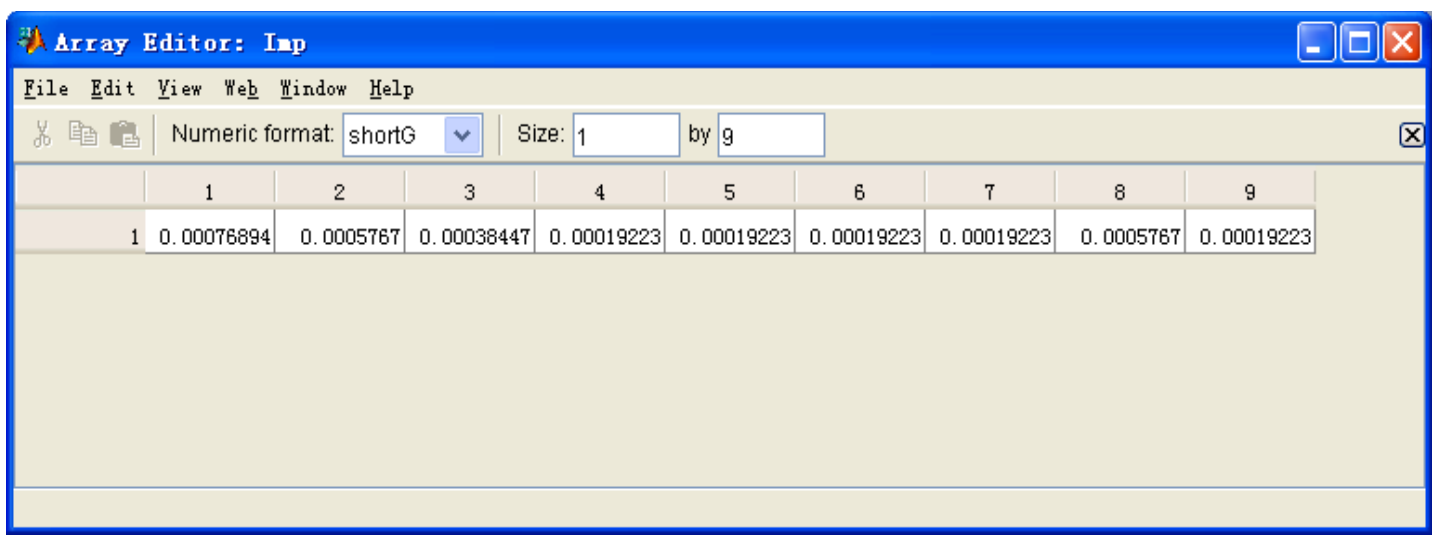

(Figure 2 influence factors's importance computed by program)

\section{(2) Further analysis to results}

(1) The result shows that cooperation attitude ranks third. Software developing is base on top-down decomposition layer modular architecture, different modules are integrated with stated interface and standards. Certain adjustment could be done well on the basis of favorable cooperation and communication among the developing teams. Employee belong to different teams or firms maybe never meet each other during the cooperative process, so completion of the task relies more on other connection ways (kinds of electronic ways).

(2) From figure 2, quality of employee, developing conditions, communication ways, the atmosphere of learning and creation and support from management would definitely bring some positive effect on VSC' operation. During the period, developing enviornment, management's support are crucial for smooth communication of firms or employee, at the same time, responsibility and attitude for work are also significant.

\section{Conclusion}

The motive of forming VSC is pursing a better completion of software developing task than any single software enterprise, for VSC can make use of all advantages of partners' firms. During cooperation process, lack of cooperative efficency may lead to failure of the task which isn't the original intention of VSC. This paper strives to find out the influence factors of VSCs' operation, so, necessary studies have been done by adopting factor analysis method and RST based on gathered data through questionnaire survey. At the end of this paper, some effective suggestions are put forth according to the analytic results.

\section{References}

[1] XuPei, ZhangRenJun, How to create effective project team[J]. Statistics and desicion, 2005 (3 ): 132 133

[2] KangZhuang, Study on Project managementb methods of Software developing [D] . Master's degree paper of University of International Business and Economics, 2006 